\title{
Computerized cycle analysis of harvest, transport, and unload systems
}

\author{
Dennis R. Buckmaster*, James W. Hilton \\ Agricultural and Biological Engineering, 230 Agricultural Engineering Building, \\ The Pennsylvania State University, University Park, PA 16802, USA
}

Received 21 November 2003; received in revised form 12 May 2004; accepted 21 November 2004

\begin{abstract}
Cycle diagrams are relatively simple tools that can provide insight concerning the interaction of equipment and operational changes on dynamic agricultural systems. However, they are tedious to generate by hand which makes it time consuming to compare system alternatives. Cycle analysis principles were implemented in a spreadsheet so machine and system performance variables can be quickly evaluated. The template can be used to evaluate harvesters with and without on-board storage as well as harvesters that can and cannot unload while harvesting. Machine capacity, operational data and parameter inputs are required for each machine and operation. Outputs include cycle time, system capacity, and idle time for each machine. Efficiency measures of harvester, transporter, unloader, and labor utilization (h work of work per $\mathrm{h}$ real time) are computed. Often, the harvester is the most expensive machine, so an evaluation of its actual field efficiency (compared to what it could do if other factors were non-limiting) can be enlightening. An equation for required transport capacity to fully utilize a harvester is derived.
\end{abstract}

(C) 2004 Elsevier B.V. All rights reserved.

Keywords: Capacity; Cycle analysis; Harvest; Machinery selection; Transport

\footnotetext{
* Corresponding author. Tel.: +1 8148653392.

E-mail address: drb3@psu.edu (D.R. Buckmaster).
} 


\section{Introduction}

Systems analysis is a tool commonly used by engineering and system management professionals to determine the impact of changes and machine interactions within the system. Systems analysis can use data sets and operational scenarios to represent system capacities, relationships, and interactions. Systems analysis protocol and programming can often be expensive and can be cumbersome since system specific programs typically require input and output parameters and isolated system functions associated with each individual situation.

Selection of machinery sets for agricultural field work has been accomplished with modeling and optimization approaches; specific software with decision-making and educational value has been written. Selection of machinery for use in sequential operations requires consideration of timeliness, capacity, probability of suitable days, and length of workdays (Lavoie et al., 1991; Parmar et al., 1996; Rotz et al., 1983; Siemens et al., 1990). Selection of machinery used in simultaneous operations requires consideration of the cycle time and capacity of each machine. Cycle diagrams (Hunt, 1986), are simple diagrammatic tools that can be used to review single scenario systems. Cycle diagrams have been used in many industries to analyze operating systems that have equipment interactions. They are practical for evaluating individual machine capacity and efficiency in the context of system performance; effects of individual machine performance on other machines and total system performance are elucidated. Manually constructed cycle diagrams help conceptual understanding, but are tedious to generate. The next logical step is to compare system alternatives which can be very time consuming (and is often not done). Cycle analysis has been implemented in complex simulation models of agricultural systems (e.g., Rotz et al., 1989), but it has not been used as a tool for selecting and analyzing alternative agricultural machinery systems.

The use of cycle diagrams to illustrate the interaction of machines within a system is a good starting point from which to introduce and analyze machine systems. Diagrams are easily illustrated and completed following a few simple rules governing their use. Incorporating the computational structure of cycle diagram analysis into a spreadsheet creates a powerful tool to facilitate system analysis. Inputs can be easily varied to evaluate alternative systems and plot results showing sensitivity of performance to input data. The objectives of this work were to provide a spreadsheet implementation for rapid cycle analysis of agricultural harvest/transport/unload systems and illustrate cycle analysis application by determining reasonable transport capacity requirements for self-propelled forage harvesters.

\section{Model structure}

The principles and developmental steps governing the use of cycle diagrams were outlined by Hunt (1986). To manually draw a cycle diagram and perform an analysis, the developmental steps are:

1. Sketch the cycle to show the proper machine relationships. 
2. Mark the support times between individual machine cycles with a zigzag line. Mark both machine loops at their points of interaction.

3. Sum the cycle times required for each machine loop and select the largest to be the system cycle time.

4. Add idle times to the other machine loops to bring their total times up to the total system time. Identify this on the diagram with circles.

5. Field efficiency can now be estimated more accurately when the machine in question is a part of the system.

Outputs from a cycle analysis include system capacity, labor efficiency, and utilization rates for each machine. Basic relationships for capacity and associated parameter ranges for typical field speeds and field efficiencies are required for this analysis and are included in ASAE Standards (ASAE, 2002a, 2002b, 2002c). Table 1 illustrates the spreadsheet implementation of cycle analysis accompanying the cycle diagram of Fig. 1 (a self-propelled

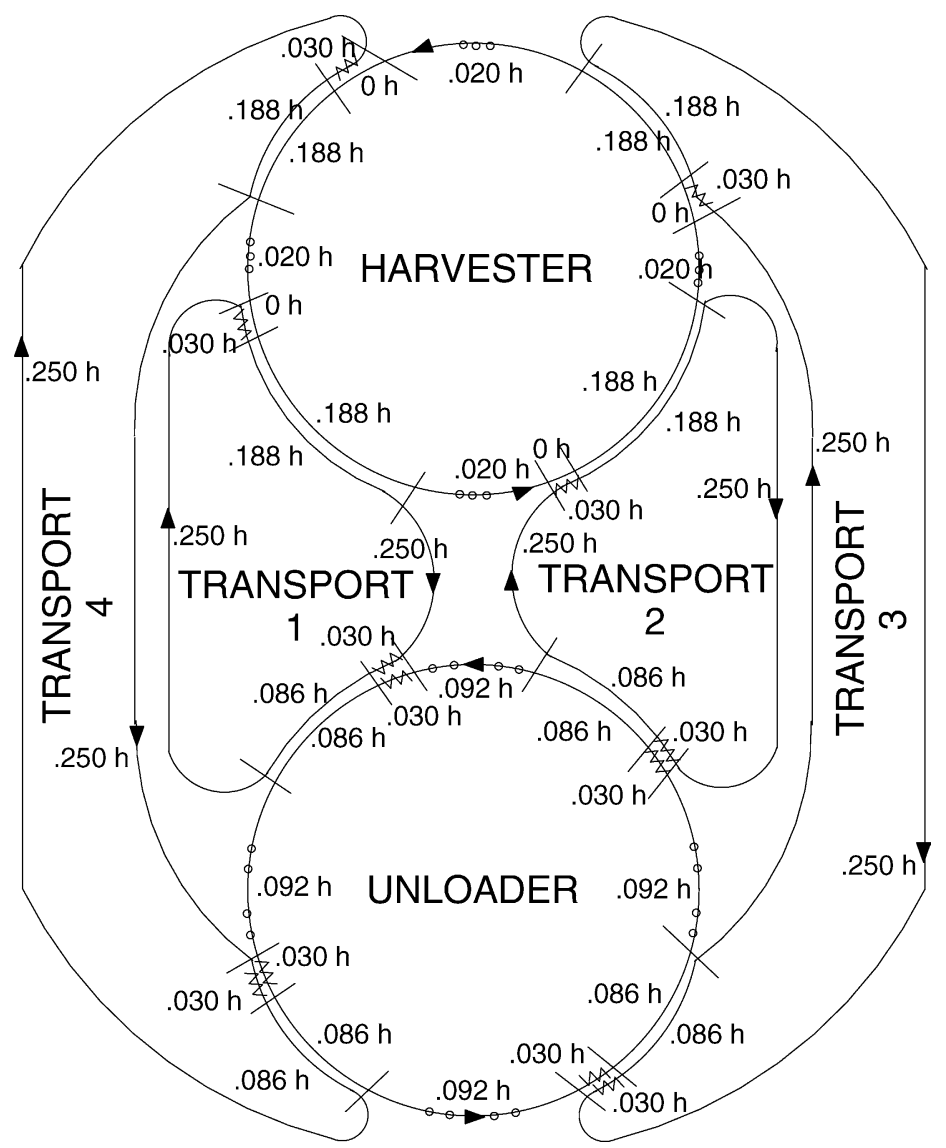

Fig. 1. Cycle diagram for the one harvester, four-transporter system of Table 1. Alignment is indicated with zigzag lines and idle time is indicated with circles. 
Table 1

Cycle diagram analysis of system capacity and efficiency; spreadsheet implementation of the cycle analysis (includes baseline analysis for the example forage harvest/transport/unload system)

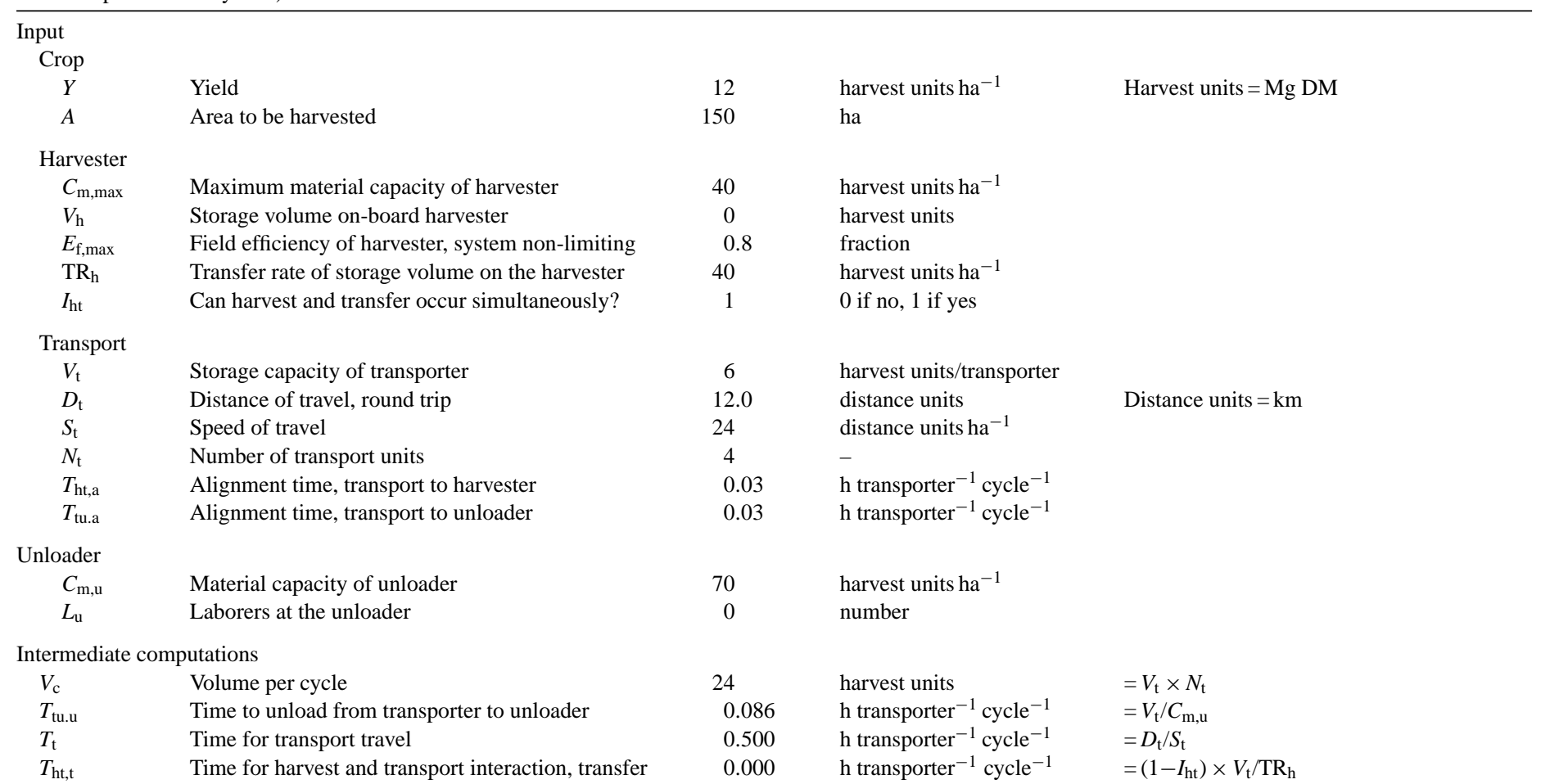


Table 1 (Continued)

\begin{tabular}{|c|c|c|c|c|}
\hline$T_{\mathrm{ht}, \mathrm{h}}$ & Time for harvest and transport interaction, harvesting & 0.188 & $\mathrm{~h}$ transporter ${ }^{-1}$ cycle $^{-1}$ & $=\mathrm{IF}\left(V_{\mathrm{t}}>V_{\mathrm{h}},\left(V_{\mathrm{t}}-V_{\mathrm{h}}\right) /\left(C_{\mathrm{m}, \max } \times E_{\mathrm{f}, \max }\right), 0\right)$ \\
\hline $\mathrm{CT}_{\mathrm{h}}$ & Cycle time for harvester without idle time & 0.750 & h cycle ${ }^{-1}$ & $=V_{\mathrm{c}} /\left(C_{\mathrm{m}, \max } \times E_{\mathrm{f}, \max }\right)+T_{\mathrm{ht}, \mathrm{t}} \times N_{\mathrm{t}}$ \\
\hline $\mathrm{CT}_{\mathrm{t}}$ & Cycle time for transporter without idle time & 0.803 & h cycle cy $^{-1}$ & $=T_{\mathrm{tu}, \mathrm{a}}+T_{\mathrm{tu}, \mathrm{u}}+T_{\mathrm{ht}, \mathrm{t}}+T_{\mathrm{ht}, \mathrm{h}}+T_{\mathrm{t}}$ \\
\hline $\mathrm{CT}_{\mathrm{u}}$ & Cycle time for unloader without idle time & 0.463 & h cycle ${ }^{-1}$ & $=N_{\mathrm{t}} \times\left(T_{\mathrm{tu}, \mathrm{a}}+T_{\mathrm{tu}, \mathrm{u}}\right)$ \\
\hline$T_{\mathrm{i}, \mathrm{h}}$ & Idle time of harvester & 0.083 & h cycle ${ }^{-1}$ & $\begin{array}{l}=\mathrm{IF}\left(\mathrm{CT}_{\mathrm{t}}+T_{\mathrm{ht}, \mathrm{a}}>\mathrm{CT}_{\mathrm{h}}+N_{\mathrm{t}} \times T_{\mathrm{ht}, \mathrm{a}}\right. \\
\left.\mathrm{CT}-\mathrm{CT}_{\mathrm{h}}-N_{\mathrm{t}} \times T_{\mathrm{ht}, \mathrm{a}}, \mathrm{CT}-\mathrm{CT}_{\mathrm{h}}\right)\end{array}$ \\
\hline$T_{\mathrm{i}, \mathrm{t}}$ & Idle time of transport unit & 0.000 & h cycle ${ }^{-1}$ & $\begin{array}{l}=\mathrm{IF}\left(\mathrm{CT}_{\mathrm{t}}+T_{\mathrm{ht}, \mathrm{a}}>\mathrm{CT}_{\mathrm{h}}+N_{\mathrm{t}} \times T_{\mathrm{ht}, \mathrm{a}}, \mathrm{CT}-\mathrm{CT}_{\mathrm{t}},\right. \\
\left.\mathrm{CT}-\mathrm{CT}_{\mathrm{t}}-T_{\mathrm{ht}, \mathrm{a}}\right)\end{array}$ \\
\hline$T_{\mathrm{i}, \mathrm{u}}$ & Idle time of unloader & 0.370 & h cycle ${ }^{-1}$ & $=\mathrm{CT}-\mathrm{CT}_{\mathrm{u}}$ \\
\hline$L$ & Laborers working & 5.000 & - & $=1+N_{\mathrm{t}}+L_{\mathrm{u}}$ \\
\hline$L_{\mathrm{i}}$ & Labor idle time & 0.083 & h cycle ${ }^{-1}$ & $=T_{\mathrm{i}, \mathrm{h}}+N_{\mathrm{t}} \times T_{\mathrm{i}, \mathrm{t}}+L_{\mathrm{u}} \times T_{\mathrm{i}, \mathrm{u}}$ \\
\hline \multicolumn{5}{|l|}{ Outputs } \\
\hline$U_{\mathrm{h}}$ & Utilization of harvester & 0.90 & $\mathrm{~h}$ harvest $\mathrm{h}^{-1}$ & $=V_{\mathrm{c}} /\left(C_{\mathrm{m}, \max } \times E_{\mathrm{f}, \text { max }}\right) / \mathrm{CT}$ \\
\hline$U_{\text {ta }}$ & Utilization of transporter - travel only & 0.60 & $\mathrm{~h}$ travel $\mathrm{h}^{-1}$ transporter $^{-1}$ & $=T_{\mathrm{t}} / \mathrm{CT}$ \\
\hline$U_{\mathrm{tb}}$ & Utilization of transporter - overall & 1.00 & $\mathrm{~h}$ busy $\mathrm{h}^{-1}$ transporter $^{-1}$ & $=\left(\mathrm{CT}-T_{\mathrm{i}, \mathrm{t}}\right) / \mathrm{CT}$ \\
\hline$U_{\mathrm{ub}}$ & Utilization of unloader-overall & 0.56 & h busy $h^{-1}$ & $=\mathrm{CT}_{\mathrm{u}} / \mathrm{CT}$ \\
\hline UL & Utilization of labor & 0.98 & $\mathrm{~h}$ working $\mathrm{h}^{-1}$ & $=1-L_{\mathrm{i}} /(L \times \mathrm{CT})$ \\
\hline$C_{\text {sys,a }}$ & Material capacity of the system & 28.8 & harvest units $\mathrm{h}^{-1}$ & $=U_{\mathrm{h}} \times E_{\mathrm{f}, \max } \times C_{\mathrm{m}, \max }$ \\
\hline$E_{\text {f,h.act }}$ & Actual field efficiency of the harvester & 0.72 & fraction & $=C_{\mathrm{sys}, \mathrm{a}} / C_{\mathrm{m}, \max }$ \\
\hline$T$ & Total time to get the job done & 62 & $\mathrm{~h}$ & $=Y \times A / C_{\text {sys }, \mathrm{a}}$ \\
\hline$L_{\mathrm{t}}$ & Total labor to get the job done & 312 & $\mathrm{~h}$ & $=L \times T$ \\
\hline$C_{\text {sys,b }}$ & Material capacity of the system, a check & 28.8 & harvest units $\mathrm{h}^{-1}$ & $=V_{\mathrm{c}} / \mathrm{CT}$ \\
\hline
\end{tabular}


forage harvester scenario). The units in the spreadsheet implementation are generic (e.g., harvest units $\mathrm{h}^{-1}$ ). Users need to maintain unit consistency throughout the problem statement and solution (e.g., harvest units $=\mathrm{kg}$, distance units $=\mathrm{km}$ ) to obtain valid output.

With one cycle representing a "round" by all transport units, the volume per cycle is computed from the volume per transporter and the number of transporters (note nomenclature, all variable definitions with units, and equations are included in Table 1):

$$
V_{\mathrm{c}}=V_{\mathrm{t}} \times N_{\mathrm{t}}
$$

\subsection{System components}

The productive portion of a harvester's cycle consists of harvest time and interaction time with the transporter. The primary contributor to the harvester's cycle time is the time to harvest the material per cycle which is a function of volume per cycle, maximum harvester capacity, and maximum field efficiency.

In low-yield situations, it may not be possible to reach theoretical throughput of a harvester; in these cases, the maximum harvester capacity achievable regardless of the transport and unload system is important. In cases where there is on-board storage on the harvester, another possible contributor is time to transfer material from the harvester to the transporter(s); this is a function of the amount of material to transfer and the transfer rate from the harvester. An indicator variable for simultaneous harvest and transfer was used to accommodate situations, where "on the go" material transfer from harvester to transporter can occur.

Another possible contributor to the harvester's cycle time is the interaction time to allow for alignment with the transporter(s). This is assumed to be zero for either the harvester or the transporter(s) - whichever has no idle time. That is, the alignment is the responsibility of the unit, which is least busy.

Productive transporter time is spent interacting with the harvester and the unloader plus transit time to and from the field. Interaction time with the unloader is a combination of alignment and working time. Transit time is simply a function of distance and speed. There is a possibility that the harvester cannot completely fill the transporter with material harvested and held in on-board storage. In this case, some additional harvest time must be added to the transporter cycle.

Productive unloading time is spent with the transporter(s) during alignment or unloading.

\subsection{System integration}

The system total cycle time is the maximum of the cycle times of system components prior to idle time consideration. The total cycle time represents the amount of time for all components in the system to "handle" the capacity of all units combined. With time required to align the harvester and transporter assigned to the less busy machine, system total cycle time and idle time of harvesters and transporters are functions of component cycle times (see Table 1). 
It is assumed that the harvester and transporter(s) have a worker assigned to them. The unloader may or may not require a laborer. Labor idle time is:

$$
L_{\mathrm{i}}=T_{\mathrm{i}, \mathrm{h}}+N_{\mathrm{t}} \times T_{\mathrm{i}, \mathrm{t}}+L_{\mathrm{u}} \times T_{\mathrm{i}, \mathrm{u}}
$$

where $L_{\mathrm{i}}$ is idle time for labor, h cycle ${ }^{-1}$ and $L_{\mathrm{u}}$ is the number of laborers at the unloader.

Time utilization efficiency of each unit, as well as labor, is computed from theoretical capacities, minimal component cycle times, and actual system total cycle time.

$$
\begin{aligned}
& U_{\mathrm{h}}=\frac{V_{\mathrm{c}} /\left(C_{\mathrm{m}, \text { max }} \times E_{\mathrm{f}, \max }\right)}{\mathrm{CT}} \\
& U_{\mathrm{ta}}=\frac{T_{\mathrm{t}}}{\mathrm{CT}} \\
& U_{\mathrm{tb}}=\frac{\mathrm{CT}-T_{\mathrm{ti}, \mathrm{t}}}{\mathrm{CT}} \\
& U_{\mathrm{ua}}=\frac{V_{\mathrm{c}} / C_{\mathrm{m}, \mathrm{u}}}{\mathrm{CT}} \\
& U_{\mathrm{ub}}=N_{\mathrm{t}} \times \frac{T_{\mathrm{tu}, \mathrm{a}}+T_{\mathrm{tu}, \mathrm{u}}}{\mathrm{CT}} \\
& \mathrm{UL}=1-\frac{L_{\mathrm{i}}}{L \times \mathrm{CT}}
\end{aligned}
$$

System capacity, with the operating cycle considered, is:

$$
C_{\text {sys }}=\frac{V_{\mathrm{c}}}{\mathrm{CT}}
$$

This approach for cycle analysis (particularly the spreadsheet implementation) could be expanded into an optimization tool by adding marginal cost of additional capacity to the analysis. In the existing system analysis framework, however, it remains a useful educational and decision tool. With a slight change of perspective (and hence terminology), the same relationships can also be used to analyze load, transport, and distribute systems such as spraying or planting. An example would be a self-propelled sprayer fed by a nurse truck loaded at the chemical plant. As presented, the analysis is applicable to harvest systems for grains, forages, vegetables, or fruits with system interactions between the harvester, transporter(s), and unloading sites. 


\section{Sample analysis}

A common agricultural equipment scenario of forage harvest was used to illustrate the use of cycle analysis in spreadsheet form. This system illustrated here involves machines that harvest, transport, and unload harvested forage crops. This harvesting scenario was used because of the relative simplicity and the clarity of the relationships between individual machines and the complete system. This example also demonstrates the ability to make scenario modifications and evaluate alternative systems; e.g., varying transporter number or size while holding the harvester fixed or varying the harvester while holding the transport system fixed.

For the self-propelled forage harvesting system evaluated, the harvester had a maximum theoretical material capacity of $40 \mathrm{Mg} \mathrm{DM} \mathrm{h}^{-1}$ with a maximum field efficiency (transporter non-limiting) of $80 \%$ (ASAE, 2002c; Table 1). This represents a $235 \mathrm{~kW}$ (315 hp) harvester harvesting whole-plant corn silage at $65 \%$ moisture. Varying transporter numbers and capacities are evaluated with the unloader capacity significantly larger than the harvester capacity. With three transporters each having $8 \mathrm{Mg} \mathrm{DM}(8.8 \mathrm{t} \mathrm{DM})$ capacity, the transport system limited system capacity to $26.8 \mathrm{Mg} \mathrm{DMh}^{-1}\left(29.5 \mathrm{t} \mathrm{DMh}^{-1}\right)$; this limited the harvester to a field efficiency of $67 \%$. Labor utilization was excellent at $98 \%$. With all inputs identical except for use of four $6 \mathrm{Mg} \mathrm{DM}(6.6 \mathrm{t} \mathrm{DM})$ capacity transporters, system capacity increased to 28.8 $\mathrm{Mg} \mathrm{DM} \mathrm{h}^{-1}$ (Table 1); the harvester field efficiency increased to $72 \%$. Labor utilization remained at $98 \%$. Similarly, with six $4 \mathrm{Mg}$ DM (4.4 t DM) transporters, system capacity, harvester field efficiency, and labor utilization were $32.0 \mathrm{Mg} \mathrm{DM} \mathrm{h}^{-1}\left(35.2 \mathrm{tDM} \mathrm{h}^{-1}\right), 80 \%$, and $99 \%$, respectively. The optimum from these transport alternatives depends upon the costs for operating the harvester and transport units. Generally, however, transport units are less expensive per unit capacity than harvesters; the scenario with the highest economic efficiency will likely be the scenario which keeps the most expensive machine and labor most fully utilized.

System performance is sensitive to transport distance. With four 6 Mg DM (6.6 t DM) transporters, transport distances above $12 \mathrm{~km}$ ( 7.5 miles) resulted in reduced system capacity. Labor efficiency was highest in the range of $10-15 \mathrm{~km}(6.2-9.3$ miles) because the transporters and harvester were more fully utilized. For these scenarios, system capacity dropped by over $20 \%$ as transport distances exceeded $16 \mathrm{~km}$ (10 miles).

Fig. 2 illustrates how transporter capacity influenced system performance. With the $12 \mathrm{~km}$ (7.5 miles) transport distance, three $10 \mathrm{Mg} \mathrm{DM}(11 \mathrm{t} \mathrm{DM})$ transport units $(30 \mathrm{Mg}$ $\mathrm{DM}$ or $33 \mathrm{t} \mathrm{DM}$ total per cycle) were required to fully utilize the harvester's capacity. However, with four units, each transporter only needed a capacity of approximately $6 \mathrm{Mg} \mathrm{DM}$ (6.6t DM).

For a particular harvest capacity, identification of a suitable transport system required an analysis of the number and size of transporters for varying transport distances. For the $12 \mathrm{~km}$ ( 7.5 miles) distance and other inputs of Table 1, system capacity was plotted versus number and size of transporters (Fig. 3). With an ancillary evaluation of marginal costs for larger or more transporters, this plot could easily be used as a decision making tool. 

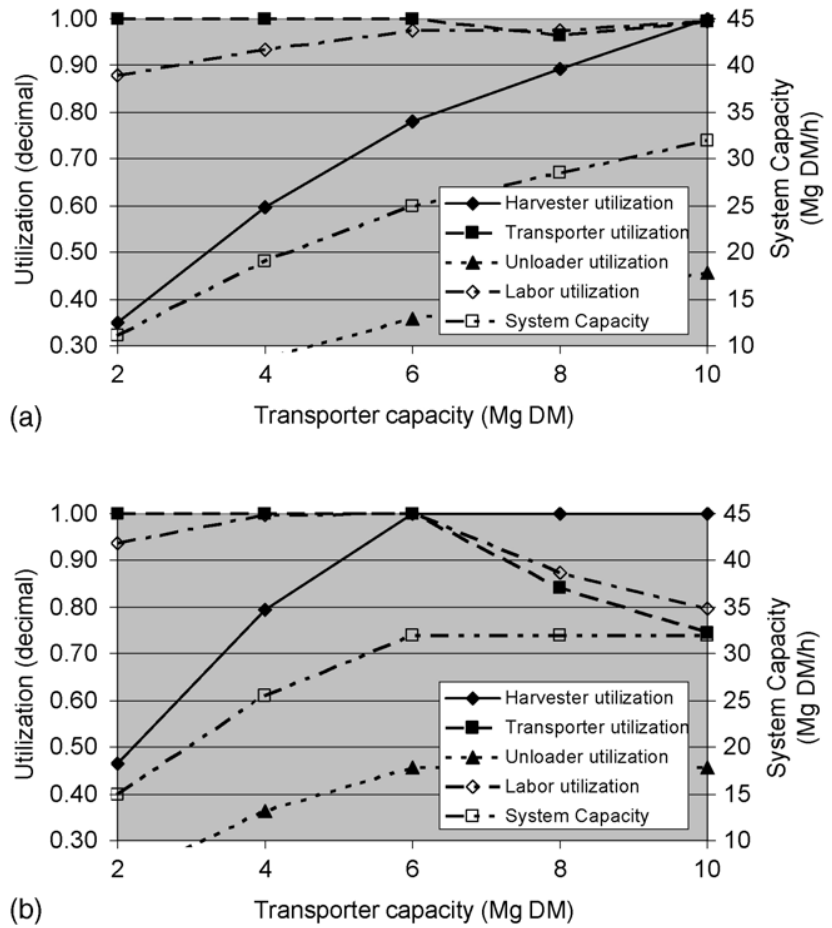

Fig. 2. Effect of transporter capacity on forage harvest system performance with a $40 \mathrm{Mg} \mathrm{DMh}^{-1}$ forage harvester and $12 \mathrm{~km}$ round-trip transport distance (inputs of Table 1 except for transporter capacity: (a) three transporters and (b) four transporters).

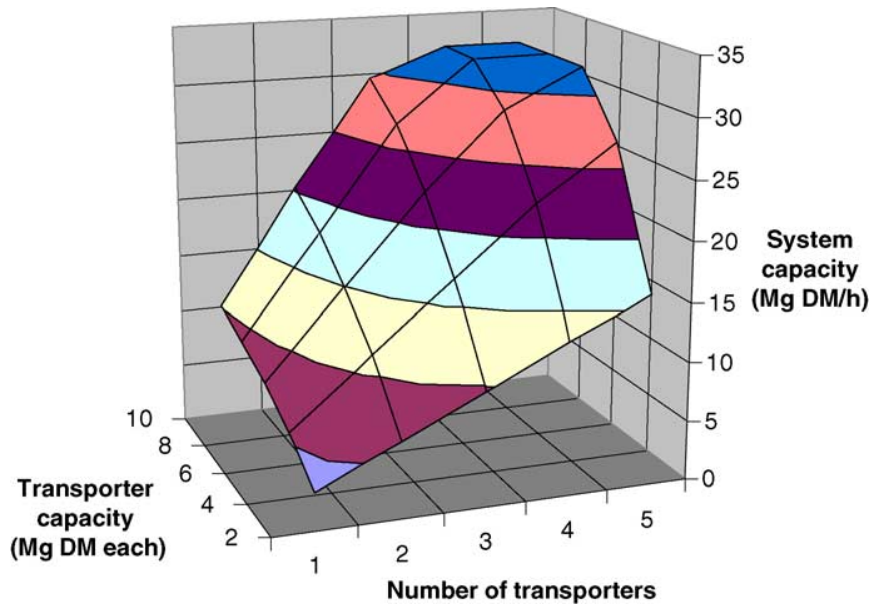

Fig. 3. Effect of transporter number and size on system capacity with a $40 \mathrm{Mg} \mathrm{DM} \mathrm{h}^{-1}$ forage harvester (inputs of Table 1 except for transporter number and size). 


\section{Transporter capacity requirement}

Transporter capacity "requirement" could be determined directly from the cycle time relationships. If the harvester is to be utilized completely $\left(U_{\mathrm{h}}=1.00\right)$, the cycle time of the harvester will be the cycle time of the system. Therefore,

$$
\mathrm{CT}=\mathrm{CT}_{\mathrm{h}}=T_{\mathrm{h}}+T_{\mathrm{ht}, \mathrm{t}} \times N_{\mathrm{t}}
$$

From the transporter perspective, then:

$$
\mathrm{CT}=T_{\mathrm{tu}, \mathrm{a}}+T_{\mathrm{tu}, \mathrm{u}}+T_{\mathrm{ht}, \mathrm{t}}+T_{\mathrm{ht}, \mathrm{h}}+T_{\mathrm{t}}+T_{\mathrm{ht}, \mathrm{a}}
$$

Setting these two equal to each other can lead to a relationship for minimum transporter size required to keep the harvester fully utilized (for a particular scenario). With a simplifying assumption that transporter capacity matches on-board storage capacity of the harvester if the harvester has on-board storage, this relationship for transporter capacity, which keeps a harvester fully utilized, is:

$$
V_{\mathrm{t}}=\frac{T_{\mathrm{tu}, \mathrm{a}}+D_{\mathrm{t}} / S_{\mathrm{t}}+T_{\mathrm{ht}, \mathrm{a}}+V_{\mathrm{h}} /\left(C_{\mathrm{m}, \max } \times E_{\mathrm{f}, \max }\right)}{\left.\left(N_{\mathrm{t}}-1\right) / C_{\mathrm{m}, \max } \times E_{\mathrm{f}, \max }\right)+\left(N_{\mathrm{t}}-1\right)\left(1-I_{\mathrm{ht}}\right) / \mathrm{TR}_{\mathrm{h}}-1 / C_{\mathrm{m}, \mathrm{u}}}
$$

\section{Conclusions}

A spreadsheet implementation was developed and used with students that accommodates harvesters with and without on-board storage in situations where harvest and transfer of material may or may not occur simultaneously. The model is presented in a manner which illustrates a sequence of computations and details relationships so users can easily evaluate alternative scenarios. By determining equipment and labor utilization, the spreadsheet sheds light on machine interactions and system capacity which may be limited by any particular system component.

The cycle analysis spreadsheet is a relatively simple and straightforward model for presentation of cycle analysis concepts; it is applicable to continuous harvest/transport/unload or load/transport/spread systems. Similar systems with batch processes such as load/process/load can also be analyzed. The model does not include an economic analysis, but could be used as an input to a larger economic model. Potential areas for expansion include addition of submodels for components of harvesting, transporting, or unloading. For example, harvester or unloader power/energy relationships or capacity limits due to speed, crop yield, available power, or traction could be incorporated; these would make the model more comprehensive for a particular situation, but more restrictive for general application.

\section{Appendix A. Availability}

The spreadsheet implementation of cycle analysis and more detailed documentation of the equations and the example herein are available on the internet at: www.abe.psu.edu/ 
fac/Buckmaster/Publ/cycleanalysis.xls. The model requires Microsoft Excel (version 97 or later).

\section{References}

ASAE, 2002a. S495. Uniform terminology for agricultural machinery management. In: ASAE Standards, 49th ed. ASAE, St. Joseph, MI.

ASAE, 2002b. EP496.2. Agricultural machinery management. In: ASAE Standards, 49th ed. ASAE, St. Joseph, MI.

ASAE, 2002c. D497.4. Agricultural machinery management data. In: ASAE Standards, 49th ed. ASAE, St. Joseph, MI.

Hunt, D.R., 1986. Engineering Models for Agricultural Production. AVI Publishing, Westport, CT.

Lavoie, G., Gunjal, K., Raghavan, G.S.V., 1991. Soil compaction, machinery selection, and optimum crop planning. Trans. ASAE 34 (1), 2-8.

Parmar, R.S., McClendon, R.W., Potter, W.D., 1996. Farm machinery selection using simulation and genetic algorithms. Trans. ASAE 39 (5), 1905-1909.

Rotz, C.A., Buckmaster, D.R., Mertens, D.R., Black, J.R., 1989. DAFOSYM: A dairy forage system model for evaluating alternatives in forage conservation. J. Dairy Sci. 72 (11), 3050-3063.

Rotz, C.A., Muhtar, H.A., Black, J.R., 1983. A multiple crop machinery selection algorithm. Trans. ASAE 26 (6), 1644-1649.

Siemens, J., Hamburg, K., Tyrell, T., 1990. A farm machinery selection and management program. J. Prod Agric. $3(2), 212-219$ 